\title{
Diseño metodológico para la definición de determinantes ambientales regionales basadas en el sistema GTP en la jurisdicción de CORPOCHIVOR ${ }^{1}$
}

\author{
Methodological design for definition of regional environmental \\ determinants based on the GTP system within the jurisdiction of \\ CORPOCHIVOR
}

Felipe Fonseca Fino ${ }^{2}$

\section{Resumen}

El artículo presenta el diseño metodológico para la definición y construcción de determinantes ambientales regionales en CORPOCHIVOR, basadas en el sistema Geosistema, Territorio y Paisaje GTP, explica sus características generales y expone las conclusiones de la investigación. Se considera que la formulación de las actuales determinantes ambientales en CORPOCHIVOR se fundamenta en una aproximación biofísica del territorio, pero carece de una comprensión integral y sistémica del ambiente. De esta forma, la adaptación de la teoría del sistema GTP (Bertrand \& Bertrand, 2006) permitió proponer una estrategia de gestión ambiental para su implementación, así como apoyar otros procesos que adelanta esta corporación.

Palabras clave: Determinantes ambientales, geografía ambiental, geosistema, paisaje, sistema GTP, territorio.

1 Fragmento de la tesis de magíster denominada Diseño de una propuesta metodológica para la definición de determinantes ambientales a escala regional a partir del sistema GTP de la jurisdicción de Corpochivor, departamento de Boyacá.

2 Magister en Geografía. Subdirector de Geografía y Cartografía, Instituto Geográfico Agustín Codazzi IGAC. Bogotá D.C.Colombia. felipefonsecaf@gmail.com 


\section{Abstract}

This paper presents the methodological design for definition and construction of regional environmental determinants in CORPOCHIVOR based on the Geosystem, Territory and Landscape, GTP system, explains its general characteristics and conclusions of the investigation. It is considered that the formulation of current environmental determinants in CORPOCHIVOR is based on a biophysical approach of the territory, but lacks an integrated and systemic comprehension of the environment. Thus, an adaptation of GTP systems theory (Bertrand \& Bertrand, 2006) allowed proposing an environmental management strategy for its implementation, as well as supporting other processes that have been conducted by this corporation.

Key words: Environmental determinants, environmental geography, geosystem, GTP system, landscape, territory. 


\section{Introducción}

Esta investigación propone un diseño metodológico para la definición y construcción de las determinantes ambientales regionales basadas en el sistema Geosistema, Territorio y Paisaje, sistema GTP, a fin de orientar la planificación ambiental regional en los municipios de la jurisdicción de la Corporación Autónoma Regional de Chivor, CORPOCHIVOR, en el departamento de Boyacá.

En Colombia, la Ley 388 de 1993 definió las determinantes de los planes de ordenamiento territorial, que constituyen normas de superior jerarquía en sus propios ámbitos de competencia y deben ser tenidas en cuenta en la elaboración y adopción de los planes de ordenamiento territorial (POT) municipal y distrital; dentro de las determinantes de los POT están las relacionadas con la conservación y protección del medio ambiente, los recursos naturales y la prevención de amenazas y riesgos naturales (Congreso de Colombia, 1997, art. 10). De acuerdo con lo anterior, CORPOCHIVOR formuló sus determinantes ambientales por medio de la Resolución 306 del 27 de julio de 1999, las cuales deben actualizarse para orientar los procesos de revisión, ajuste o modificación de los POT de su jurisdicción.

Se identificó el carácter biofísico con el cual se formularon las determinantes ambientales de CORPOCHIVOR, basado en el enfoque ecosistémico; por lo tanto, las determinantes carecen de una visión integral y sistémica del ambiente que incluya el análisis y compresión territorial, así como de elementos socioculturales fundamentales para orientar la gestión ambiental de la corporación. En palabras de Bertrand y Frolova (2006): "La comprensión integral del ambiente es compleja y amplia para ser abordada únicamente desde ópticas biocentristas de la ecología como el ecosistema o desde el geosistema, propiamente dicho".

De otra parte, el sistema GTP se presenta como un método aplicable y eficiente para la planificación de las actividades asociadas a la preservación, conservación y recuperación de los recursos naturales que allí se encuentran (Pissinati \& Archela, 2009, p. 5). Los objetivos del sistema GTP son: describir los tres conceptos o nociones espacio-temporales, identificar las relaciones e interacciones de los diferentes componentes constitutivos y, en especial, conocer la estructura y función del geosistema, territorio y el paisaje. El geosistema se considera la entrada biofísica y su grado de antropización, el territorio analiza e integra el sistema socioeconómico, y el paisaje es la entrada socio-cultural del sistema ambiental.

Esto significó una oportunidad para proponer, desde la geografía ambiental, una metodología que permita instrumentalizar el concepto del sistema GTP y aportar elementos prácticos para su aplicación, en este caso, la definición de determinantes ambientales. En consecuencia, se adaptó la teoría del sistema GTP a esta investigación, donde el geosistema aportó la zonificación biofísica y el grado de antropización para identificar ecosistemas importantes como los páramos alto-andinos con riesgo inminente 
de deterioro y en los que se deben adelantar acciones de protección, así como otras zonas de conservación, manejo sostenible y restauración que orientan acciones adecuadas para la gestión ambiental del suelo rural. La síntesis territorial identificó la caracterización político-institucional, socioeconómica, de funcionalidad y estructura municipal, concebida desde el sistema GTP como la "artificialización", para orientar la gestión de la corporación en cada entidad político-administrativa. La aproximación del paisaje socio-cultural es de carácter inductivo, es decir, desde lo local a lo regional, de lo particular a lo general.

El análisis de paisaje se hizo en una vereda de la parte alta del municipio de Úmbita, zona de importante transformación ecosistémica, para proponer una aproximación a la interpretación del espacio de los actores sociales locales desde la percepción. Desde esta óptica, el paisaje socio-cultural representa la "artialización" como forma de explicar el territorio por medio del arte visual, escrito y oral.

De esta forma, la adaptación de la teoría del sistema GTP (Bertrand \& Bertrand, 2006) en el diseño metodológico para la definición y construcción de las determinantes ambientales en CORPOCHIVOR permitió proponer una estrategia de gestión ambiental para su implementación, así como apoyar otros procesos que adelanta la corporación como el Plan de Ordenación Forestal, la determinación de Áreas Naturales Protegidas Regionales, el Plan de Lucha contra la Desertifica- ción de la Región y el fortalecimiento del Sistema de Información Ambiental Territorial SIAT. Se espera que lo propuesto permita su aplicación en otras CAR y fomente futuras investigaciones.

\section{Planteamiento del problema}

La necesidad de actualizar las determinantes ambientales de CORPOCHIVOR permitió identificar los principales problemas en su formulación: la aproximación unívoca biofísica, la falta de una metodología para la definición y construcción, así como la carencia de una comprensión integral y sistémica del ambiente acorde con la escala y ámbito de gestión ambiental. Se propuso la adaptación de la teoría del sistema GTP como sustento conceptual aportado por la geografía ambiental.

Al respecto, el artículo 10 de la Ley 388 de 1997 establece lo siguiente:

“...En la elaboración y adopción de sus planes de ordenamiento territorial los municipios y distritos deberán tener en cuenta las siguientes determinantes, que constituyen normas de superior jerarquía, en sus propios ámbitos de competencia, de acuerdo con la Constitución y las leyes: 1 . Las relacionadas con la conservación y protección del medio ambiente, los recursos naturales, la prevención de amenazas y riesgos naturales, así:

(...) 
b) Las regulaciones sobre conservación, preservación, uso y manejo del medio ambiente y de los recursos naturales renovables, en las zonas marinas y costeras; las disposiciones producidas por la Corporación Autónoma Regional o la autoridad ambiental de la respectiva jurisdicción, en cuanto a la reserva, alindamiento, administración o sustracción de los distritos de manejo integrado, los distritos de conservación de suelos, las reservas forestales y parques naturales de carácter regional; las normas y directrices para el manejo de las cuencas hidrográficas expedidas por la Corporación Autónoma Regional o la autoridad ambiental de la respectiva jurisdicción; y las directrices y normas expedidas por las autoridades ambientales para la conservación de las áreas de especial importancia ecosistémica..." (Congreso de Colombia, 1997, art. 10). (Negrillas fuera de texto)

En efecto, dentro de los instrumentos para la planificación ambiental regional de las corporaciones autónomas regionales (CAR), en el largo, medio y corto plazo, se encuentran el Plan de Gestión Ambiental Regional (PGAR), el Plan de Acción Trienal (PAT) y el Presupuesto Anual de Rentas y Gastos. Para este propósito se debe tener en cuenta que:

"Los contenidos del Plan de Gestión Ambiental Regional deben constituirse en la base para la actualización de las determinantes ambientales para los Planes de Ordenamiento Territorial, lo cual debe ser ampliamente socializado con los municipios de la Jurisdicción de la Corporación." (Ministerio de Ambiente, Vivienda y Desarrollo Territorial, 2004). (Negrillas fuera de texto)

En CORPOCHIVOR, las determinantes ambientales y los elementos articuladores se formularon mediante la Resolución 306 del 27 de julio de 1999. Su finalidad fue identificar zonas para la protección, conservación, manejo y restauración del medio ambiente y los recursos naturales. Incluye la definición de usos principales (deseables para el desarrollo sostenible), compatibles, condicionados o prohibidos (graves riesgos de tipo ecológico o social). La zonificación propuesta se orientó a partir de componentes biofísicos (bióticos, abióticos e incluso los efectos antrópicos) basados en el concepto de ecosistema.

De hecho, tal ha sido el dominio del concepto ecosistema, que es el origen del Enfoque por Ecosistemas propuesto por el Convenio sobre la Diversidad Biológica (CDB), como: “estrategia para la gestión integrada de tierras, extensiones de aguas y recursos vivos por la que se promueve la conservación y utilización sostenible de modo equitativo, aunque, reconoce que los seres humanos, con su diversidad cultural, son un componente integral de muchos ecosistemas" (Secretaría del Convenio sobre la Diversidad Biológica, 2004, p. 9). En consecuencia, 
el Enfoque por Ecosistemas es el fundamento de la planificación ambiental de las autoridades ambientales en Colombia y se constituyó como la base conceptual de carácter biocéntrico para la formulación de los planes, programas y proyectos ambientales y territoriales.

Sin embargo, no hay una visión territorial en la formulación de las determinantes que dé cuenta de la estructura y función de los municipios de la jurisdicción de CORPOCHIVOR, tampoco una caracterización municipal que los diferencie o agrupe, ni se identifica una visión sociocultural local o regional.

La incorporación de la "dimensión ambiental" en los procesos de ordenamiento y planificación territorial hace referencia a componentes biofísicos, pero no es clara la definición de lo "ambiental". Es decir, que las determinantes ambientales de CORPOCHIVOR no garantizan una compresión integral del ambiente ni del espacio geográfico, que trascienda a las relaciones que se establecen con los procesos socio-culturales, así como su manifestación espacial y temporal desde una aproximación geográfica, como la propone el sistema GTP.

De otro lado, la jurisdicción de CORPOCHIVOR hace parte de la región andina del país, la cual:

"Se ha visto sometida a una alta concentración de la población que ha ido en detrimento del valioso capital natural contenido en ella. Los cultivos, la ganadería y los centros poblados han desplazado a las masas de ecosistemas naturales, y estos cada vez tienen mayores probabilidades de desaparecer" (Rodríguez, Armenteras, Morales, \& Romero, 2004, p. 107).

Adicionalmente, la jurisdicción presenta asentamientos humanos, especialmente en las zonas urbanas donde el sector comercial genera las principales fuentes de empleo. Está ubicada en una región principalmente rural, con una economía asociada al sector agropecuario. Según CORPOCHIVOR:

“...Puede afirmarse que el desarrollo de la zona rural ha dependido de la adaptación de los procesos productivos de las comunidades a las características de los suelos (muy degradados) y del clima y no tanto de la capacidad de la población, a través de la aplicación de tecnologías para modificar las condiciones que le ofrece la naturaleza y sostener la oferta ambiental. Esto ha obligado a buscar nuevas áreas productivas, especialmente en zonas de alta fragilidad ecosistémica, con una alta fragmentación de la propiedad rural (el $92 \%$ de los predios totales de la jurisdicción son menores de 5 hectáreas y cerca del $76 \%$ son predios de menos de 1 hectárea)" (CORPOCHIVOR, 2007, p. 17; 2011, p. 14).

De lo anterior, se reconoce que los problemas ambientales derivados de procesos de transformación de ecosistemas se 
relacionan estrechamente, con diferentes intensidades, con el funcionamiento social, económico y socio-cultural del territorio.

En consecuencia, la pregunta de esta investigación es: ¿cómo pueden ser definidas y construidas metodológicamente las determinantes ambientales regionales basadas en el sistema GTP, que permitan comprender de forma integral y sistémica los componentes, relaciones, interacciones y funciones espacio-temporales que entre ellos se establecen para orientar la planificación ambiental regional en los municipios de la jurisdicción de CORPOCHIVOR, en el departamento de Boyacá?

\section{Descripción del lugar}

La jurisdicción de CORPOCHIVOR está compuesta por 25 municipios del sur del departamento de Boyacá, Colombia, y se caracteriza por ser escenario de transformación de las coberturas de la tierra originadas por el desarrollo de actividades agropecuarias. De acuerdo con la corporación, cerca del $34,2 \%$ de su territorio corresponde a tierras agrícolas (CORPOCHIVOR, 2010, p. 57). Sin embargo, según el mapa de coberturas de la tierra (Instituto de Hidrología, Meteorología y Estudios Ambientales de Colombia [IDEAM] et al., 2011), en esta jurisdicción el 64,2 \% corresponde a territorios agrícolas. La corporación estima que el $80 \%$ del área de la cuenca hidrográfica del río Garagoa, principal afluente de la jurisdicción, no tiene la cobertura de sus ecosistemas originales, ya que actualmente predominan potreros, algunos cultivos, asentamientos e infraestructura.

La complejidad en la dinámica natural del territorio está íntimamente relacionada con la incidencia de las transformaciones asociadas principalmente a los cambios en el uso del suelo y a las actividades humanas que en las últimas décadas han generado a su vez variaciones en los elementos, procesos y dinámicas que intervienen en la zonificación espacial ambiental (biofísicos, sociales, económicos, culturales, político-administrativos); lo que evidencia la importancia y necesidad de revisar y ajustar las propuestas de uso y ocupación del territorio a partir del análisis del medio geográfico de manera integral y sistémica.

\section{Metodología}

La metodología utilizada fue de tipo analítica, propositiva y transversal. De análisis y síntesis, porque se analizó cada una de las variables seleccionadas (síntesis, subsíntesis, componentes) por medio de los datos obtenidos en la investigación, y de síntesis porque se sumó y compendió el conjunto de elementos considerados. Se recurrió al apoyo de métodos geoestadísticos y herramientas de SIG para establecer una calificación de la importancia de cada variable y así poder ponderar al momento de integrar y sintetizar los resultados. Los modelos conceptuales propuestos tuvieron en cuenta la escala regional del estudio, la 
disponibilidad y calidad de la información y las prioridades y determinantes ambientales, consignadas en el artículo 10 de la Ley 388 de 1997 para garantizar el manejo racional de los bienes y servicios ambientales.

\section{Resultados}

El sistema GTP asocia el geosistemafuente (source), territorio-recurso (ressource) y paisaje-recurrencia resultado de la percepción (ressourcement); tiene por objeto aproximar e interactuar múltiples dimensiones para una comprensión sistémica e integral del ambiente. Como aporte de la investigación en geografía ambiental, pretende favorecer una reflexión epistemológica y conceptual para desembocar en propuestas metodológicas concretas (Bertrand \& Bertrand, 2006, p. 335).

El modelo conceptual del sistema GTP partió de comprender e interpretar lo propuesto teóricamente por Bertrand y adaptarlo al objetivo en este caso; permitió definir los componentes y requerimientos de información necesarios para cada etapa de la investigación.

La definición y construcción metodológica de las determinantes ambientales regionales identificó los componentes espacio-temporales que describieron el geosistema, territorio y paisaje, y estableció sus relaciones, interacciones y funciones para conformar el sistema GTP en la jurisdicción de CORPOCHIVOR.

El criterio para identificar los componentes del geosistema y territorio estaba basado en considerar la disponibilidad de información regional, es decir, escala general a 1:100.000, correspondiente al ámbito de la gestión de CORPOCHIVOR, y que además pueda ser replicable en otras CAR. También fue importante que la información tuviera una cobertura nacional y que fuera suministrada por entidades oficiales en la materia, como los institutos de investigación del Sistema Nacional Ambiental (SINA), el Instituto Geográfico Agustín Codazzi (IGAC), entre otros. La base cartográfica correspondió a la básica oficial suministrada por el IGAC.

El entorno del modelo conceptual del sistema GTP es abierto porque no pretendió abarcar en su totalidad la comprensión de las tres entradas principales. La aproximación conceptual y metodológica del geosistema y territorio se consideró deductiva: de lo general a lo particular; interactúa con los componentes biofísicos y socio-económicos que a su vez están relacionados entre sí con la estructura de cada sistema. A continuación se presenta el modelo conceptual del sistema GTP propuesto para la jurisdicción de CORPOCHIVOR (Figura 1).

La percepción del paisaje socio-cultural se consideró inductiva, su representación se hizo por medio de la expresión artística. El paisaje es comprendido de lo particular a lo general. Por lo anterior, fue necesario seleccionar un área en particular a escala local como caso de estudio del paisaje desde la interpretación de lo percibido por los actores sociales. La vereda se tomó como el espacio apropiado 
Figura 1. Modelo conceptual del geosistema.

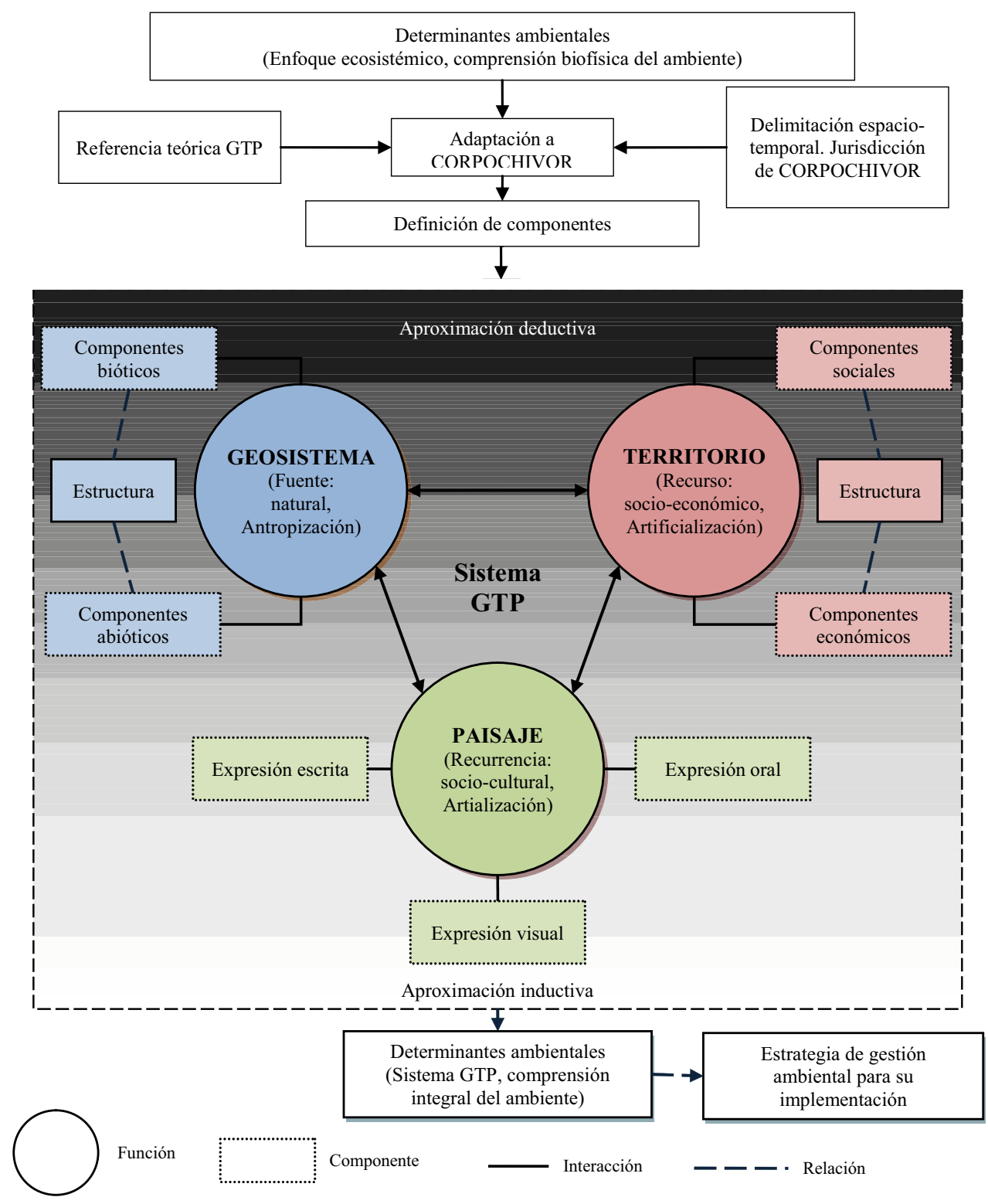

Fuente: elaboración propia. 
para este efecto, por tal razón se limitó a una sola vereda en un municipio que permitiera proponer diferentes estrategias de expresión y que fuera representativa de la transformación ecosistémica y socio-cultural. Esta condición la presentó el municipio de Úmbita que, debido a que desarrolla una intensa actividad agrícola en la parte alta, ha deteriorado los páramos de la región. Este conflicto se puede evidenciar en algunas veredas como Tásvita. Las estrategias propuestas para la materialización del paisaje fueron: la expresión escrita, oral y visual. La inmaterialidad del paisaje bertrandiano fomenta el uso de la creatividad y la didáctica para su definición.

Desde la óptica del sistema GTP, el geosistema es un concepto naturalista que permite analizar los sistemas naturales a partir del conocimiento de la estructura y el funcionamiento biofísico de un espacio geográfico determinado, tal como opera actualmente, es decir, con su grado de antropización. El geosistema es la unidad síntesis de los componentes bioclima, geomorfología y suelo (capacidad de uso de la tierra), ecosistema, bioma (conjunto de ecosistemas) y cobertura de la tierra.

La función del geosistema fue proveer una zonificación biofísica que oriente la gestión del suelo rural e identifique los diferentes ecosistemas, en particular los mayormente naturales, para su protección y conservación en la jurisdicción de CORPOCHIVOR. Véase el modelo conceptual del geosistema en la Figura 2.
En consecuencia, la zonificación biofísica es el resultado del análisis geosistémico de la jurisdicción de CORPOCHIVOR. Se identificaron distintas categorías de manejo como zonas de protección (ecosistemas de páramo), conservación, manejo sostenible y restauración (Figuras 3 y 4). Estas propuestas de manejo se presentan en las determinantes ambientales.

A partir del análisis de conflictos en el uso de la tierra y la identificación de ecosistemas mayormente naturales, se establecieron categorías de manejo en distintas zonas. Los siguientes criterios orientaron la zonificación biofísica:

- Los ecosistemas de páramo deben cuidarse, por lo tanto se proponen como zonas de protección.

- Las coberturas de la tierra o ecosistemas naturales o seminaturales deben preservarse, en consecuencia corresponden a zonas de conservación.

- Si se presenta sobreutilización como conflicto en el uso de la tierra, se propone como zona de restauración.

- Si no hay conflicto por uso de la tierra puesto que se efectúan actividades agropecuarias en suelos que lo admiten, entonces se orienta a la sostenibilidad y, por lo tanto, se considera como zona de manejo sostenible. 
Figura 2. Cobertura vegetal y usos del suelo en el año 1989

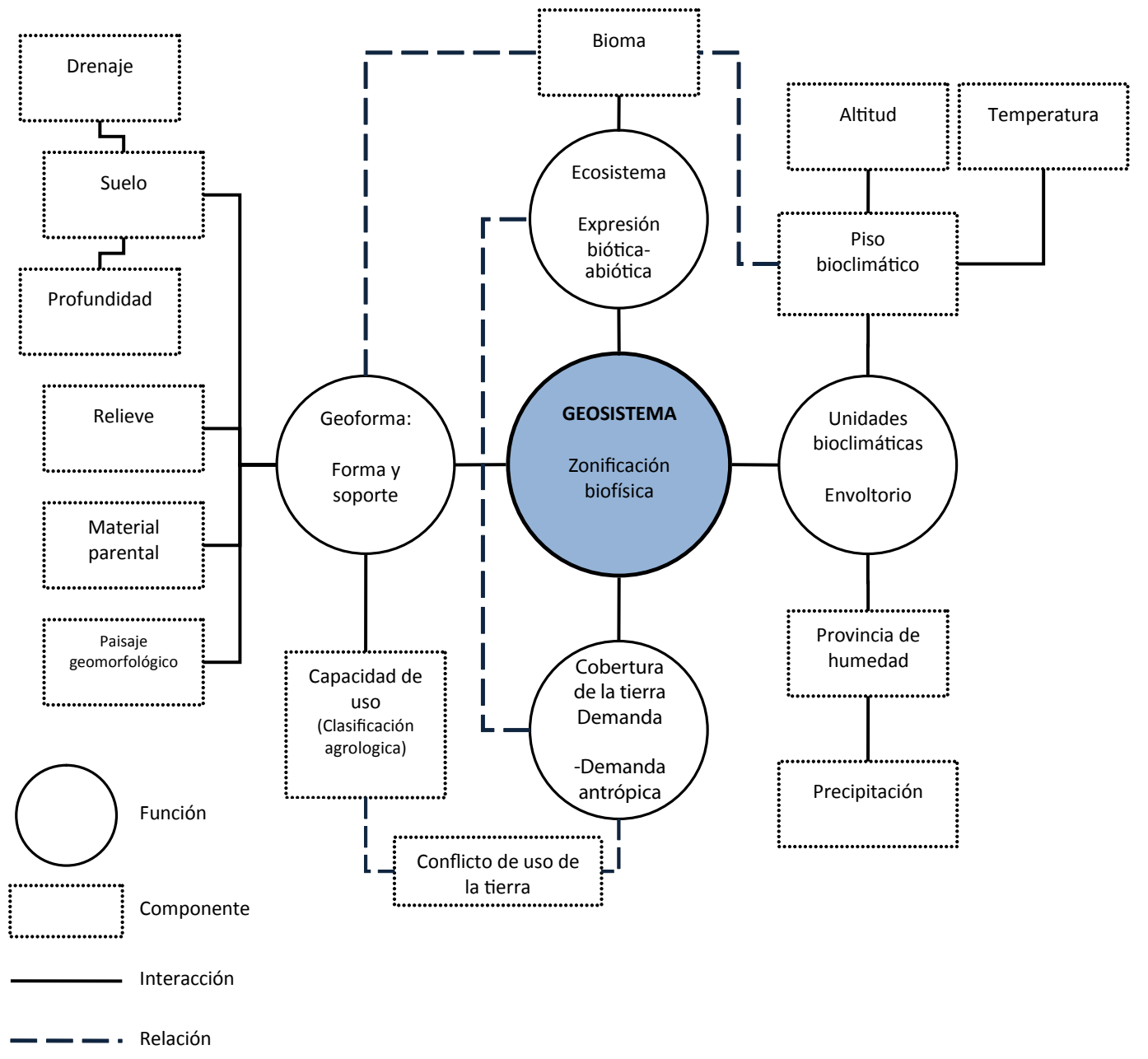

Fuente: elaboración propia 
Figura 3. Metodología para la zonificación biofísica de la jurisdicción de CORPOCHIVOR.

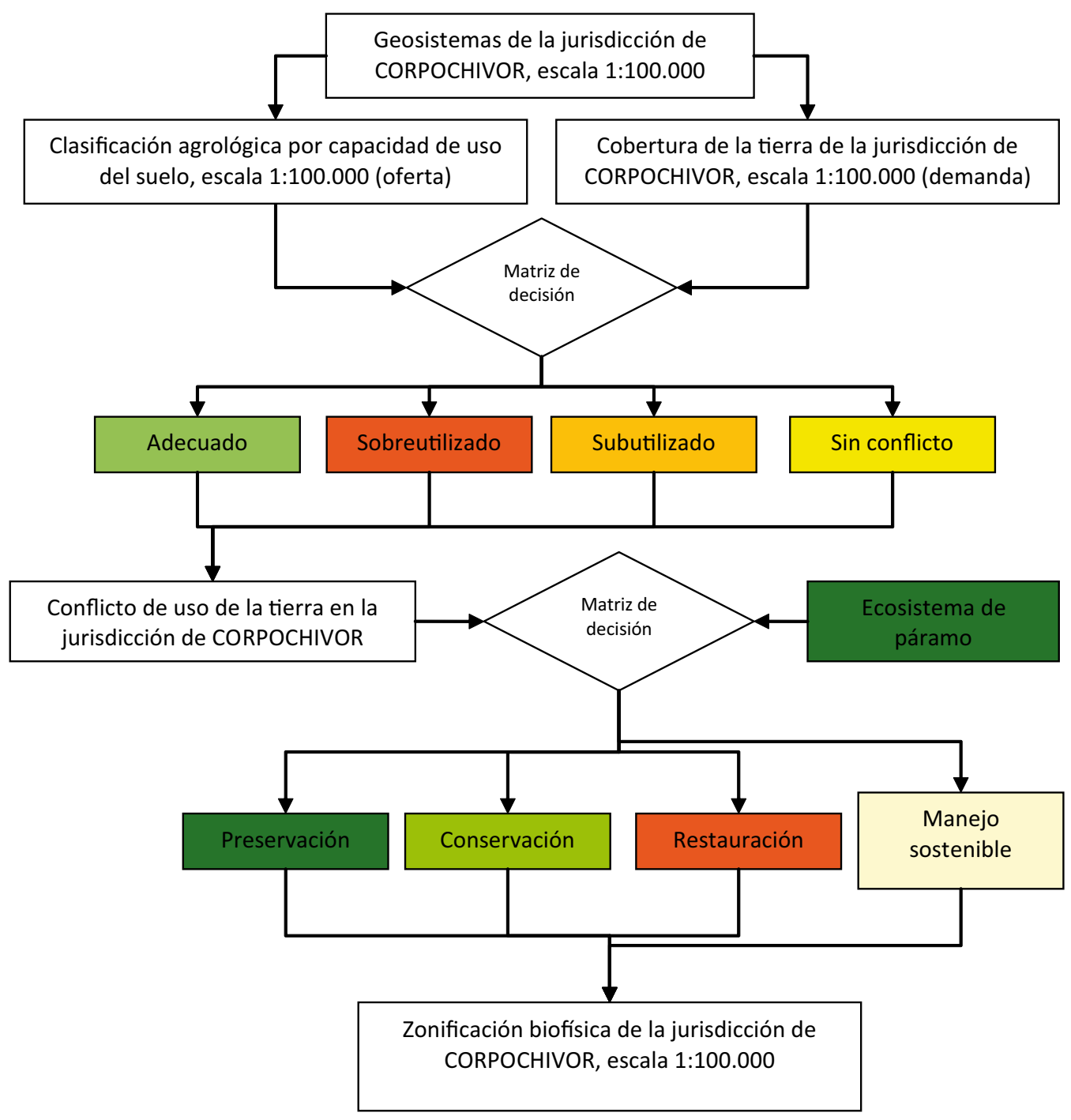

Fuente: elaboración propia 
Figura 4. Zonificación biofísica de la jurisdicción de CORPOCHIVOR.

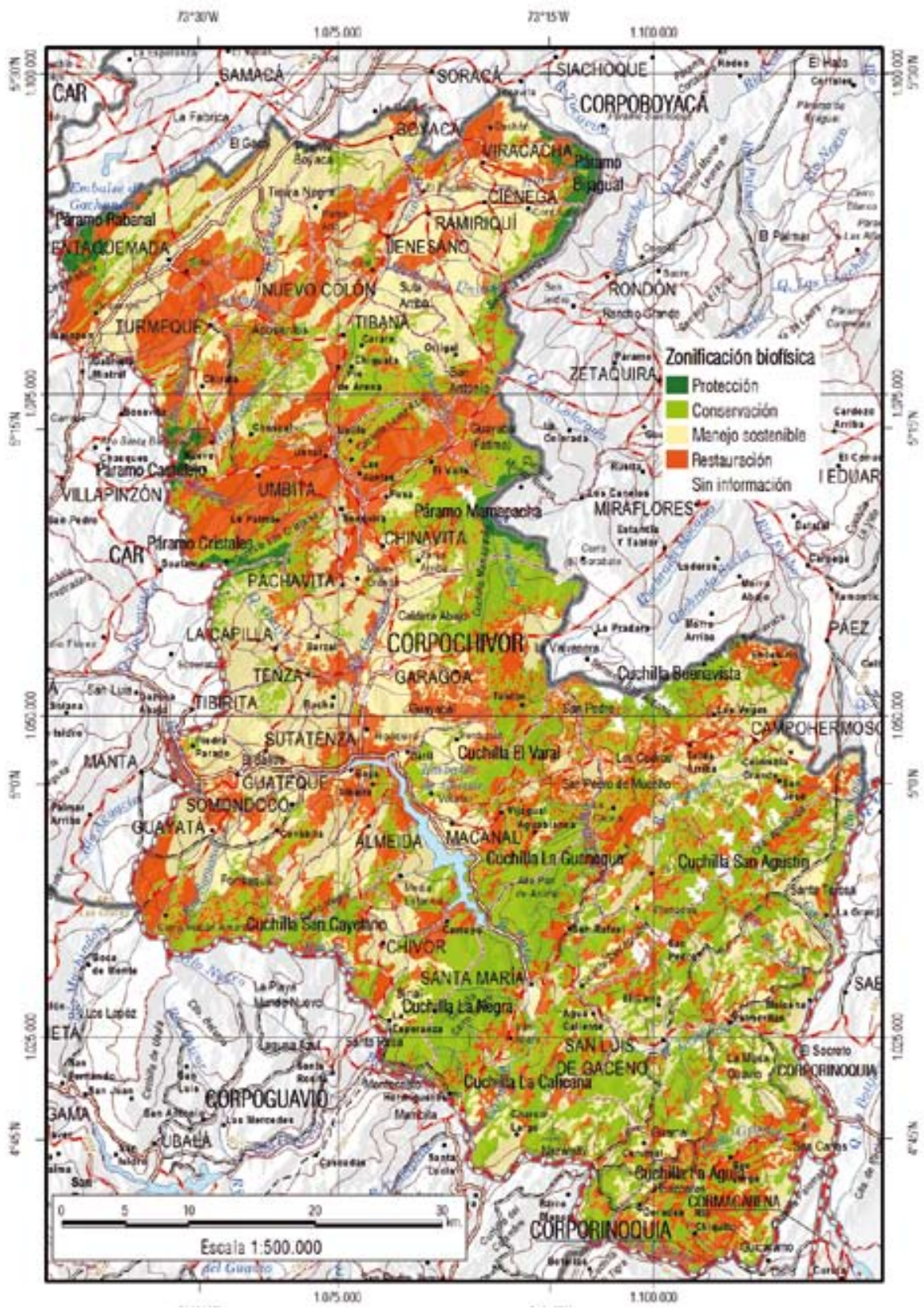

Fuente: elaboración propia; IGAC. 
De acuerdo con Frolova y Bertrand (2006): "El concepto de territorio, trata el espacio geográfico como 'recurso' (ressource) y se basa en los procesos de 'artificialización' del medio ambiente. Este concepto permite analizar las repercusiones de la organización y del funcionamiento social y económico sobre el espacio considerado".

Para la jurisdicción de CORPOCHIVOR, la propuesta de caracterización territorial fue producto de la valoración y sistematización de la información estratégica y el conocimiento disponible de la región. La principal fuente conceptual y de información socioeconómica fue el Sistema de Información Geográfica para la Planeación y el Ordenamiento Territorial, SIGOT (Instituto Geográfico Agustín Codazzi [IGAC], 2010). Se propusieron cuatro síntesis del territorio: político-institucional, económica, social y funcional, y estructura territorial. Cada síntesis se describió por medio de subsíntesis y componentes, según un modelo conceptual que identifica relaciones, interacciones y funciones del territorio (véanse la Figura 5 y la Tabla 1).

La síntesis territorial debe orientar la construcción de una visión regional integral que favorezca la gobernabilidad para el desarrollo sostenible local. Introducir un enfoque territorial en la gestión rural de la corporación es la base para implementar el principio que orienta la planeación y el ordenamiento ambiental regional y municipal: la búsqueda de una distribución equitativa de los beneficios $\mathrm{y}$ las oportunidades.
El territorio se presenta como principal concepto y función del análisis. Se identifican tres componentes que interactúan y expresan el territorio, son las síntesis o dimensiones político-institucional, económica y social, y una cuarta es la síntesis funcional y estructura territorial, que se relaciona con las anteriores para configurar y describir el funcionamiento del territorio.

Vale anotar que se trató de un ejercicio de conocimiento multidimensional del territorio, es decir, que se refirió a todas las dimensiones o sistemas y aspectos de la realidad regional, y permitió la identificación de territorios homogéneos, así como la caracterización y comprensión de su situación y sus dinámicas: homogeneidades geográficas, similitudes y diferencias socioeconómicas, etc. 
Figura 5. Modelo conceptual del territorio para la jurisdicción de CORPOCHIVOR.

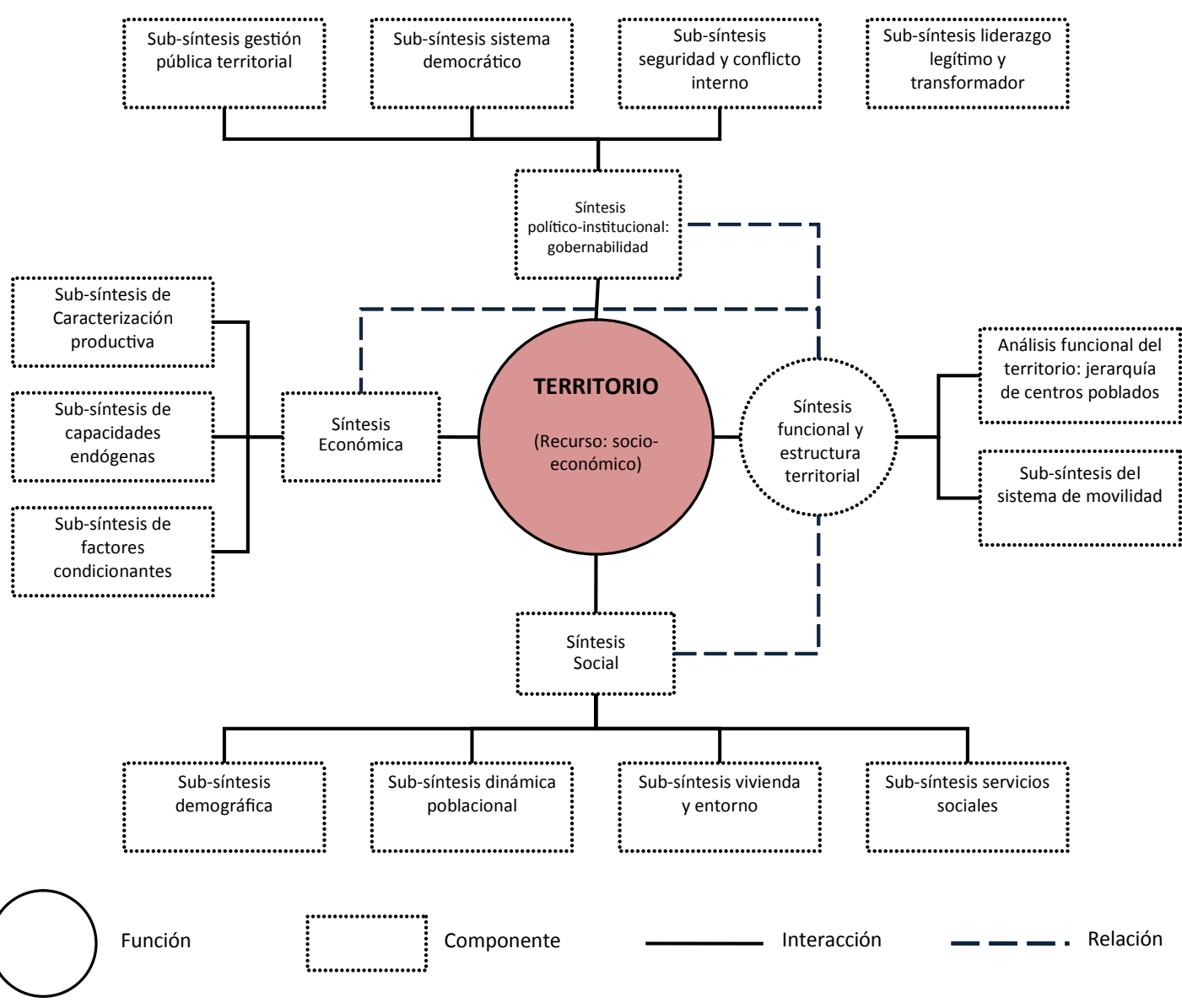

Fuente: elaboración propia. 
Tabla 1. Componentes para la caracterización del territorio en la jurisdicción de CORPOCHIVOR

\begin{tabular}{|c|c|c|c|}
\hline Síntesis & Sub-síntesis & & Componentes \\
\hline \multirow{7}{*}{$\begin{array}{l}\text { Político- } \\
\text { institucional }\end{array}$} & \multirow{2}{*}{ Gestión pública territorial } & $\begin{array}{l}\text { Tamaño y estructura } \\
\text { municipal }\end{array}$ & $\begin{array}{l}\text { Ingreso municipal/PIB departamental, Ingresos } \\
\text { públicos per-cápita }\end{array}$ \\
\hline & & $\begin{array}{l}\text { Desempeño de la } \\
\text { gestión municipal }\end{array}$ & $\begin{array}{l}\text { Índice de desempeño fiscal, Desempeño integral } \\
\text { municipal, Gestión municipal }\end{array}$ \\
\hline & Sistema democrático & \multicolumn{2}{|r|}{ Participación electoral } \\
\hline & \multirow{3}{*}{$\begin{array}{l}\text { Seguridad y conflicto } \\
\text { interno }\end{array}$} & Desplazamiento forzado & Hogares expulsados, Hogares recibidos \\
\hline & & \multicolumn{2}{|c|}{ Tasa de homicidios/100.000 hab. } \\
\hline & & \multicolumn{2}{|r|}{ Confrontaciones armadas } \\
\hline & $\begin{array}{l}\text { Liderazgo legítimo y } \\
\text { transformador }\end{array}$ & \multicolumn{2}{|r|}{ NBI rural, IVC rural } \\
\hline \multirow{9}{*}{ Económica } & \multirow{3}{*}{$\begin{array}{l}\text { Caracterización } \\
\text { productiva }\end{array}$} & Sector primario & Producción agrícola, producción ganadera \\
\hline & & Sector secundario & Pequeña industria, Microindustria \\
\hline & & Sector terciario & Comercio, Servicios \\
\hline & \multirow{5}{*}{ Capacidades endógenas } & \multirow{2}{*}{$\begin{array}{l}\text { Ciencia y tecnología en } \\
\text { el tejido socioeconómico }\end{array}$} & Nivel educativo técnico y profesional \\
\hline & & & Cobertura total de telefonía \\
\hline & & $\begin{array}{l}\text { Organización } \\
\text { urbano-regional }\end{array}$ & $\begin{array}{l}\text { Densidad vial, Densidad población urbana, } \\
\text { Cobertura rural de energía eléctrica }\end{array}$ \\
\hline & & $\begin{array}{l}\text { Instituciones modernas y } \\
\text { eficaces }\end{array}$ & $\begin{array}{c}\text { Índice de capacidad administrativa, } \\
\text { Índice de eficacia administrativa, } \\
\text { Entidades bancarias }\end{array}$ \\
\hline & & $\begin{array}{l}\text { Seguridad social y } \\
\text { pública }\end{array}$ & $\begin{array}{c}\text { Cobertura rural de acueducto, Cobertura bruta en } \\
\text { educación, Tasa de homicidios }\end{array}$ \\
\hline & Factores condicionantes & Estructura predial & $\begin{array}{l}\text { Tamaño promedio predios rurales vs. UAFpm, } \\
\text { Índice de Gini-propietarios }\end{array}$ \\
\hline \multirow{4}{*}{ Social } & Demográfica & \multicolumn{2}{|c|}{ Relación de dependencia, Tamaño promedio del hogar } \\
\hline & Dinámica poblacional & \multicolumn{2}{|c|}{$\begin{array}{l}\text { Tasa de crecimiento intercensal, Densidad de población rural, Densidad de } \\
\text { población urbana, Desplazamiento forzado }\end{array}$} \\
\hline & Vivienda y entorno & \multicolumn{2}{|c|}{$\begin{array}{l}\text { Déficit de vivienda total, Calidad de la vivienda rural, } \\
\text { Cobertura rural de acueducto, Cobertura rural de alcantarillado }\end{array}$} \\
\hline & Servicios sociales & \multicolumn{2}{|c|}{$\begin{array}{l}\text { Tasa de mortalidad infantil, Vacunación, } \\
\text { Cobertura bruta en educación, Tasa de analfabetismo }\end{array}$} \\
\hline \multirow{7}{*}{$\begin{array}{l}\text { Funcional y } \\
\text { estructura } \\
\text { territorial }\end{array}$} & \multirow{6}{*}{$\begin{array}{l}\text { Análisis funcional del } \\
\text { territorio }\end{array}$} & $\begin{array}{l}\text { Distribución espacial de } \\
\quad \text { la población }\end{array}$ & $\begin{array}{l}\text { Población total, Distribución urbano-rural, Tasa } \\
\text { de crecimiento intercensal }\end{array}$ \\
\hline & & $\begin{array}{l}\text { Distribución espacial } \\
\text { de las actividades } \\
\text { económicas }\end{array}$ & $\begin{array}{l}\text { Concentración establecimientos industriales, } \\
\text { Concentración actividad comercial, } \\
\text { Concentración establecimientos de servicios, } \\
\text { Concentración producción agropecuaria }\end{array}$ \\
\hline & & $\begin{array}{l}\text { Distribución espacial } \\
\text { de los factores de } \\
\text { competitividad }\end{array}$ & $\begin{array}{c}\text { Consumo de energía eléctrica no residencial, } \\
\text { Densidad telefónica, Densidad de servicios } \\
\text { bancarios, Accesibilidad }\end{array}$ \\
\hline & & \multirow{3}{*}{$\begin{array}{l}\text { Distribución espacial } \\
\text { de los equipamientos } \\
\text { sociales }\end{array}$} & Equipamientos de salud \\
\hline & & & Equipamientos de educación \\
\hline & & & Población escolar \\
\hline & Sistema de movilidad & \multicolumn{2}{|r|}{ Tránsito promedio diario } \\
\hline
\end{tabular}

Fuente: elaboración propia; adaptado de SIGOT (2010) 
La caracterización del funcionamiento espacial y la estructura territorial en la jurisdicción de CORPOCHIVOR (Figura 6) se basó en un escalograma funcional del territorio para establecer la jerarquía de los centros poblados, a partir de la comprensión de la distribución espacial de la población, las actividades económicas, los factores de competitividad y los equipamientos sociales y de servicios, así como el análisis del sistema de movilidad. El escalograma facilitó el análisis de funciones para el desarrollo regional.

Figura 6. Análisis funcional del territorio: jerarquía de centros poblados.

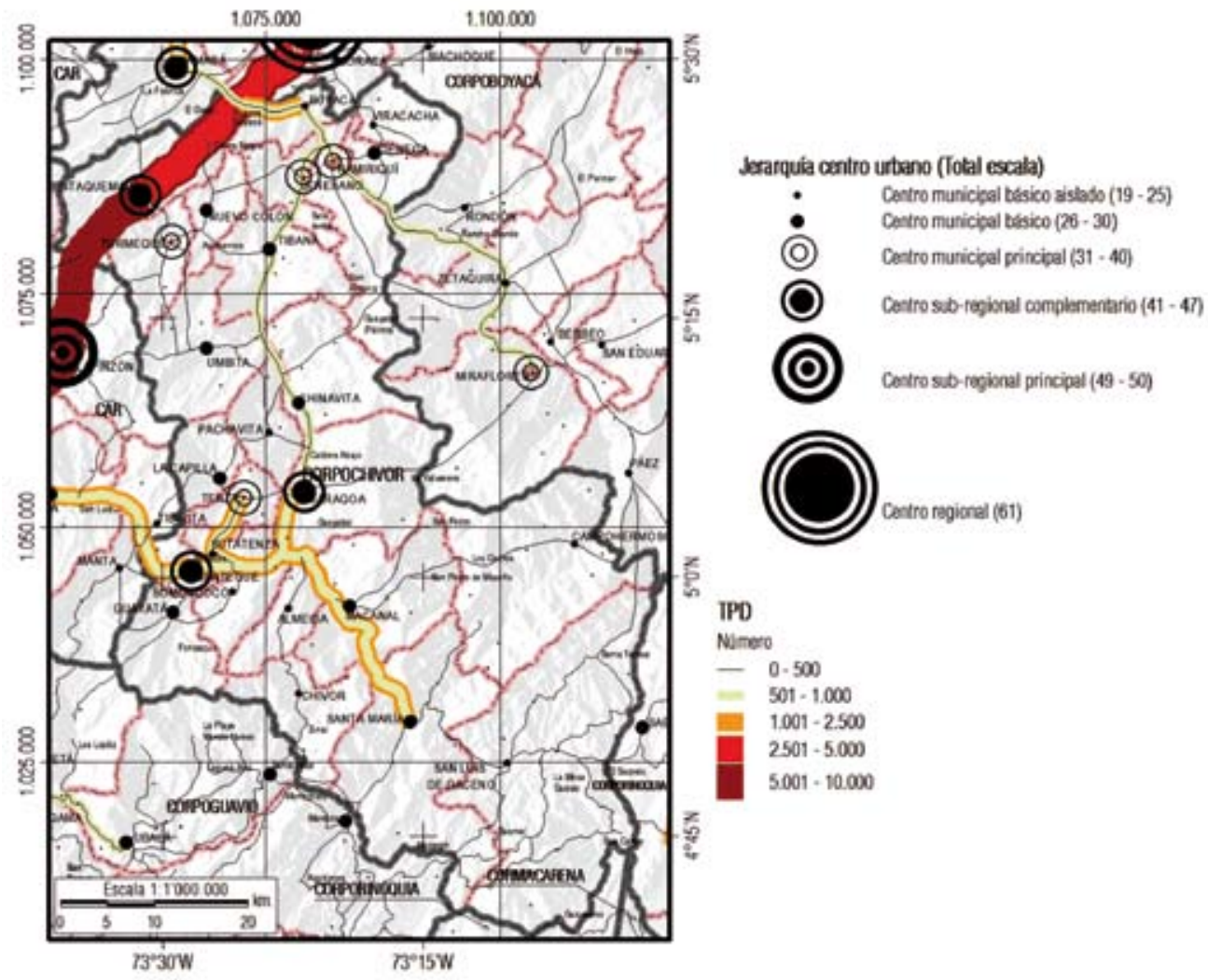

Fuente: elaboración propia. 
De acuerdo con Bertrand (2006): "El paisaje no puede ser ignorado en el desarrollo de políticas ambientales de planificación y ordenación del territorio. El paisaje representa la calidad de vida y la identidad ciudadana. El sistema GTP no agota la totalidad de la noción del paisaje".

Entonces, la reflexión que aporta el concepto del paisaje socio-cultural, desde el enfoque del sistema GTP, exigió tanto un cambio en la escala de aproximación como de metodología. Este paisaje es intangible, y su comprensión requiere de la cercanía, familiaridad y reconocimiento de una identidad cultural apegada al lugar, a lo local, para poder interpretar desde la percepción de los actores sociales que habitan en el. No es posible adquirir una mirada regional del paisaje sin transitar desde lo local. Se puede descubrir a partir de la riqueza del conocimiento inductivo, de lo particular a lo general, una posible abstracción hacia el paisaje regional.

Los componentes del paisaje materializaron los elementos más representativos del espacio geográfico que no son captados por el geosistema o territorio. La percepción social del paisaje proviene de la sensibilidad y cultura personal. Por esto, se recurrió al arte y a la expresión artística escrita, visual y oral, entre otras, para su aproximación. Por lo tanto, fueron válidas todas las formas de expresión como componentes del paisaje: la entrevista, la fotografía, el dibujo, los esquemas, la tradición cultural reflejada en la música y su letra, etc.
El modelo conceptual del paisaje se basó en el mismo del sistema GTP por una importante razón: la aproximación al paisaje socio-cultural necesitó de la comprensión del contexto y fue aportado por el geosistema (en lo biofísico) y el territorio (en lo socio-económico). La información y el conocimiento contextual permitieron una mayor referencia para el acercamiento desde lo local al paisaje, como se propone en esta metodología. Geosistema y territorio cumplen su función e interactúan con el paisaje como fenómeno "artializado", constituyéndose en una entrada de igual relevancia en el sistema GTP. A continuación se presenta el modelo conceptual del paisaje, como propuesta para la materialización y aproximación inductiva de los componentes socio-culturales (véase Figura 7).

La expresión oral se desarrolló mediante entrevistas con actores sociales que habitan en el paisaje estudiado, así como con la expresión musical que transmite en sus letras: símbolos, representaciones, tradición y cultura propios de su identidad; la expresión visual del dibujo y la fotografía permitieron representar lo inmaterial que se escapa del geosistema y territorio. Hubo un acercamiento a la riqueza de lo local en cuanto a la manifestación y el resultado de la percepción. La expresión escrita retomó lo oral y visual para transmitir las ideas, sensaciones y apreciaciones. Se transformaron en palabras los sentimientos, los anhelos y esa aparente banalidad de lo cotidiano. 
En palabras de Bertrand (2006):

“...Sin duda, las categorías sociales (urbanas, rurales) y profesionales (urbanistas, técnicos forestales, políticos, agricultores, etc.) son dignas de consideración, pero con prudencia y en beneficio de inventarios individuales. ¡Existen técnicos forestales-pintores y promotores-poetas! El paisaje no pertenece a ninguna disciplina en particular y la geografía no tiene nada que reivindicar, sino aportar su contribución a una metodología no solamente interdisciplinaria, sino también interprofesional, porque concierne, en principio, a urbanistas, arquitectos, paisajistas, sin olvidar a los que toman las decisiones políticas y administrativas. El paisaje no es, por tanto, un concepto científico y no puede ser tratado como tal. Pero esto no impide que la investigación deba sacar de él vías de estudio...".

Figura 7. Modelo conceptual del paisaje.

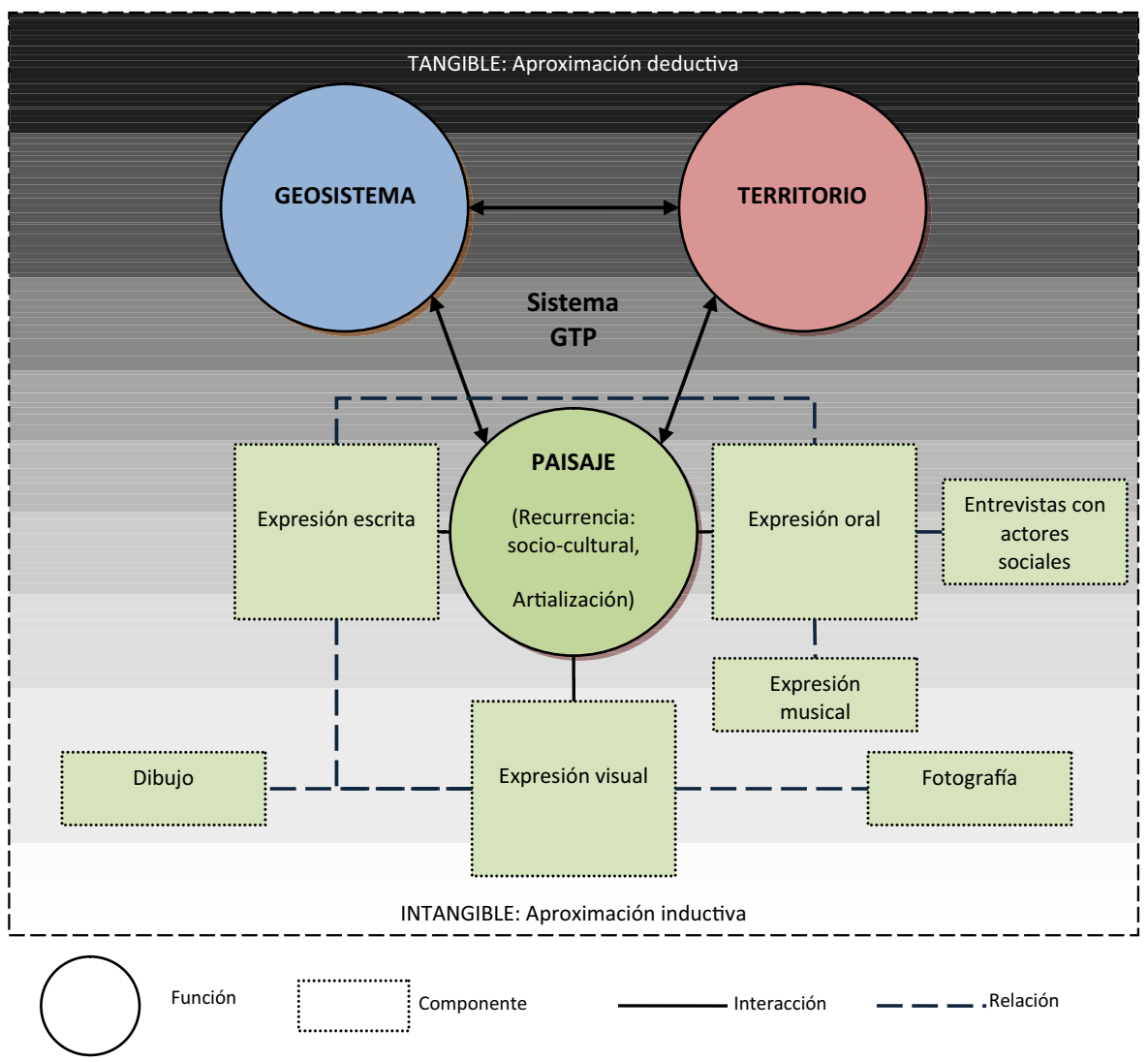

Fuente: elaboración propia. 
En este punto hay que reconocer una primera conclusión: la aproximación al paisaje requiere del trabajo interdisciplinar y por esta razón lo que aquí se propuso es, por demás, mejorable, y se insiste en que no se pretendió abarcar la plenitud del concepto de paisaje sino aportar lo que la creatividad permite.

La definición de determinantes ambientales regionales para la jurisdicción de CORPOCHIVOR se basó en el análisis del sistema geosistema, territorio y paisaje, GTP. El geosistema aportó la zonificación biofísica que identificó ecosistemas importantes como los páramos alto-andinos que presentan riesgo inminente de deterioro y en los que se deben adelantar acciones de protección, así como otras zonas de conservación, manejo sostenible y restauración que orientan acciones adecuadas para la gestión ambiental del suelo rural en la jurisdicción de CORPOCHIVOR.

La síntesis territorial ofreció la caracterización socioeconómica, de funcionalidad y estructura municipal, concebida desde el sistema GTP como la arficialización, que orienta la gestión de la corporación en cada entidad políticoadministrativa. Como se presentó en el modelo conceptual del sistema GTP, la aproximación al paisaje socio-cultural es de carácter inductivo, es decir, parte de lo local a lo regional. Por esto, y a modo de propuesta metodológica, el análisis de paisaje se hizo en la parte alta de la vereda de Tásvita, municipio de Úmbita, zona de importante transformación ecosistémica.
Las determinantes ambientales propuestas para la jurisdicción de CORPOCHIVOR son:

\section{Zonificación biofísica:}

Zonas de protección. Corresponden a ecosistemas de páramo. Son zonas cuya extensión permite su autorregulación ecológica y cuyo ecosistema en general no ha sido alterado sustancialmente por la explotación y ocupación humana, y donde las especies vegetales y animales, y las manifestaciones culturales tienen valor científico, educativo, estético y recreativo local, regional o nacional, y para su perpetuación se somete a un régimen adecuado de manejo.

Zonas de conservación. Ecosistemas naturales o mayormente naturales. Zonas que deben ser conservadas permanentemente con bosques naturales o artificiales. Su finalidad es mantener los suelos, los bosques naturales o artificiales y demás bienes y servicios ambientales, pero donde se pueden dar usos productivos que garanticen el mantenimiento de su función ecológica.

Zonas de manejo sostenible. Agroecosistemas en zonas de uso adecuado de la tierra. Zonas en las que por razón de factores biofísicos y socioeconómicos se desarrollan actividades agropecuarias en suelos cuya vocación o aptitud agrícola lo permite y que dentro de los criterios de desarrollo sostenible se ordena, planifica y regula el manejo de los bienes y servicios ambientales que allí se encuentran. 
Zonas de restauración. Zonas con conflicto por uso de la tierra por sobreutilización. Deben someterse a un manejo orientado a la recuperación de suelos alterados o degradados y a la prevención de fenómenos que causen alteración o degradación en áreas especialmente vulnerables por sus condiciones físicas. La rehabilitación se orienta a la integración de estas zonas a la protección o conservación.

\section{La síntesis territorial es el resultado del análisis y caracterización municipal del territorio y orienta la gestión ambiental de CORPOCHIVOR (véanse Tabla 2 y Figura 8):}

Tabla 2. Análisis de la síntesis territorial

\begin{tabular}{|c|c|c|}
\hline $\begin{array}{l}\text { Consolidación } \\
\text { del territorio }\end{array}$ & Caracterización territorial & Municipios \\
\hline $\begin{array}{l}\text { Territorio } \\
\text { consolidado }\end{array}$ & $\begin{array}{l}\text { Municipios con un desarrollo territorial más estable y firme. } \\
\text { Ventaquemada presenta una alta capacidad político-institucional a } \\
\text { diferencia de Garagoa y Guateque cuya capacidad es baja y crítica, } \\
\text { respectivamente. También Ventaquemada se destaca en consolidación } \\
\text { de su desarrollo económico, mientras que Garagoa y Guateque tienen } \\
\text { un proceso de expansión en lo económico. Se destaca la situación más } \\
\text { favorable en la síntesis social con mayor densidad de población urbana, } \\
\text { mayor cobertura de servicios básicos y oferta de servicios sociales. } \\
\text { Se constituyen como centros sub-regionales complementarios ubicados } \\
\text { detrás de municipios como Tunja (centro regional) y Villapinzón (centro } \\
\text { sub-regional principal). Ventaquemada se ubica sobre la vía principal } \\
\text { entre Bogotá y Tunja, generando las principales ventajas competitivas } \\
\text { en términos funcionales para su desarrollo territorial. } \\
\text { Estos municipios representan mayor presión social por la importante } \\
\text { actividad económica, en especial agropecuaria, y cuya dinámica de po- } \\
\text { blación indica una creciente demanda de bienes y servicios ambientales, } \\
\text { aumentando el riesgo de transformación ecosistémica. }\end{array}$ & $\begin{array}{c}\text { Ventaquemada, } \\
\text { Guateque y Garagoa }\end{array}$ \\
\hline $\begin{array}{l}\text { Territorio en } \\
\text { consolidación }\end{array}$ & $\begin{array}{l}\text { Municipios que afianzan su desarrollo territorial. } \\
\text { Capacidad político-institucional media y baja. Desarrollo económico en } \\
\text { etapa de expansión. Presentan una síntesis social favorable. Tasas de } \\
\text { crecimiento positivas, mayor densidad y alta concentración de la pobla- } \\
\text { ción urbana. Mayor oferta de servicios de carácter básico y cobertura de } \\
\text { servicios sociales. } \\
\text { Son centros municipales principales. Excepto Nuevo Colón que es centro } \\
\text { municipal básico. }\end{array}$ & $\begin{array}{c}\text { Ramiriquí, } \\
\text { Jenesano, } \\
\text { Nuevo Colón, } \\
\text { Turmequé y } \\
\text { Tenza. }\end{array}$ \\
\hline $\begin{array}{l}\text { Territorio en mayor } \\
\text { formación }\end{array}$ & $\begin{array}{l}\text { Municipios que han emprendido una mayor formación para su desarrollo } \\
\text { territorial. } \\
\text { Capacidad político-institucional media y baja, en el caso de Guayatá y San- } \\
\text { ta María es crítica. Ciénega y Guayatá presentan un desarrollo económico } \\
\text { en expansión mientras que los demás municipios se encuentran en una } \\
\text { etapa de despegue. Síntesis del desarrollo social media, caracterizado } \\
\text { por tasa de crecimiento negativa baja a muy baja, proporción de población } \\
\text { urbana inferior al } 50 \% \text {. Déficits de vivienda de nivel medio y alto, y un nivel } \\
\text { intermedio de cobertura de los servicios básicos. } \\
\text { Son centros municipales básicos. }\end{array}$ & $\begin{array}{c}\text { Ciénaga, } \\
\text { Tibaná, Chinavita, } \\
\text { La Capilla, Guayatá, } \\
\text { Macanal y } \\
\text { Santa María. }\end{array}$ \\
\hline
\end{tabular}




\begin{tabular}{|c|c|c|}
\hline $\begin{array}{l}\text { Consolidación } \\
\text { del territorio }\end{array}$ & Caracterización territorial & Municipios \\
\hline $\begin{array}{l}\text { Territorio en menor } \\
\text { formación }\end{array}$ & $\begin{array}{l}\text { Municipios que empiezan a formarse para su desarrollo territorial. } \\
\text { Capacidad político-institucional media y baja, en el caso de San Luis de } \\
\text { Gaceno es crítica. Boyacá y Úmbita en expansión económica, Pachavita en } \\
\text { despegue y los demás municipios tienen desarrollo económico en forma- } \\
\text { ción. Su principal característica es la economía campesina principalmente } \\
\text { de subsistencia, con baja capacidad de generación de excedentes. } \\
\text { Caracterización de la síntesis social media y baja. Con tasas de creci- } \\
\text { miento negativa baja a muy baja, proporción de población urbana inferior } \\
\text { al } 50 \% \text {. Déficits de vivienda de nivel medio y alto, y un nivel intermedio } \\
\text { de cobertura de los servicios básicos. En el caso de Boyacá y Úmbita } \\
\text { presentan condiciones críticas que derivan en un bajo nivel de desarrollo } \\
\text { social, representado en bajas densidades y dispersión rural de la población, } \\
\text { alto déficit cuantitativo y baja calidad de la vivienda, con bajas coberturas } \\
\text { en servicios básicos y una limitada oferta de servicios sociales. } \\
\text { Son centros municipales básicos aislados, excepto Úmbita que es centro } \\
\text { municipal básico. }\end{array}$ & $\begin{array}{c}\text { Boyacá, } \\
\text { Úmbita, } \\
\text { Pachavita, } \\
\text { Somondoco y } \\
\text { San Luis de Gaceno. }\end{array}$ \\
\hline Territorio aislado & $\begin{array}{l}\text { Municipios con más limitaciones para del desarrollo territorial por su } \\
\text { condición marginal. } \\
\text { Capacidad político-institucional baja. Sutatenza presenta una economía en } \\
\text { despegue y los demás municipios tienen desarrollo económico en forma- } \\
\text { ción. Su principal característica es la economía campesina principalmente } \\
\text { de subsistencia, con baja capacidad de generación de excedentes. El } \\
\text { desempeño de la gestión municipal y la capacidad administrativa están } \\
\text { en un nivel medio a bajo. } \\
\text { La síntesis social es negativa caracterizada por condiciones críticas } \\
\text { que derivan en un bajo nivel de desarrollo social, representado en bajas } \\
\text { densidades y dispersión rural de la población, alto déficit cuantitativo y } \\
\text { baja calidad de la vivienda, con bajas coberturas en servicios básicos y } \\
\text { una limitada oferta de servicios sociales. En el caso de Campohermoso, } \\
\text { su caracterización social es media. Son centros municipales básicos } \\
\text { aislados. } \\
\text { Estos municipios representan menor presión socioeconómica dado el } \\
\text { tipo de dinámica económica de subsistencia, en especial agropecuaria, } \\
\text { y cuya dinámica de población indica una menor demanda de bienes y } \\
\text { servicios ambientales. }\end{array}$ & $\begin{array}{c}\text { Viracachá, } \\
\text { Sutatenza, } \\
\text { Almeida, } \\
\text { Chivor y } \\
\text { Campohermoso }\end{array}$ \\
\hline
\end{tabular}

Fuente: elaboración propia.

Paisaje. Caso de estudio, vereda de Tásvita en el municipio Úmbita. La vereda de Tásvita es un manto verde que desciende del páramo de Castillejo, demarcado por arbustos achaparrados que se van transformando en parches de cultivos hasta conseguir formar un mosaico en el que predominan los pastos. Es una lucha entre el hombre y la naturaleza, en la que aquel se impone con hacha y machete.
A medida que se desvanecen los relieves abruptos de las crestas montañosas, las intensidades de sus colores revelan el incesante arado de la tierra para el cultivo de la papa. Brillan sus flores, se marchitan, se expone la tierra, respira y de nuevo empieza. Grupos de obreros se arman con azadón, dispuestos hasta el cansancio por el fruto del suelo negro. Esperan que esta cosecha sea mejor. 
Figura 8. Síntesis territorial.

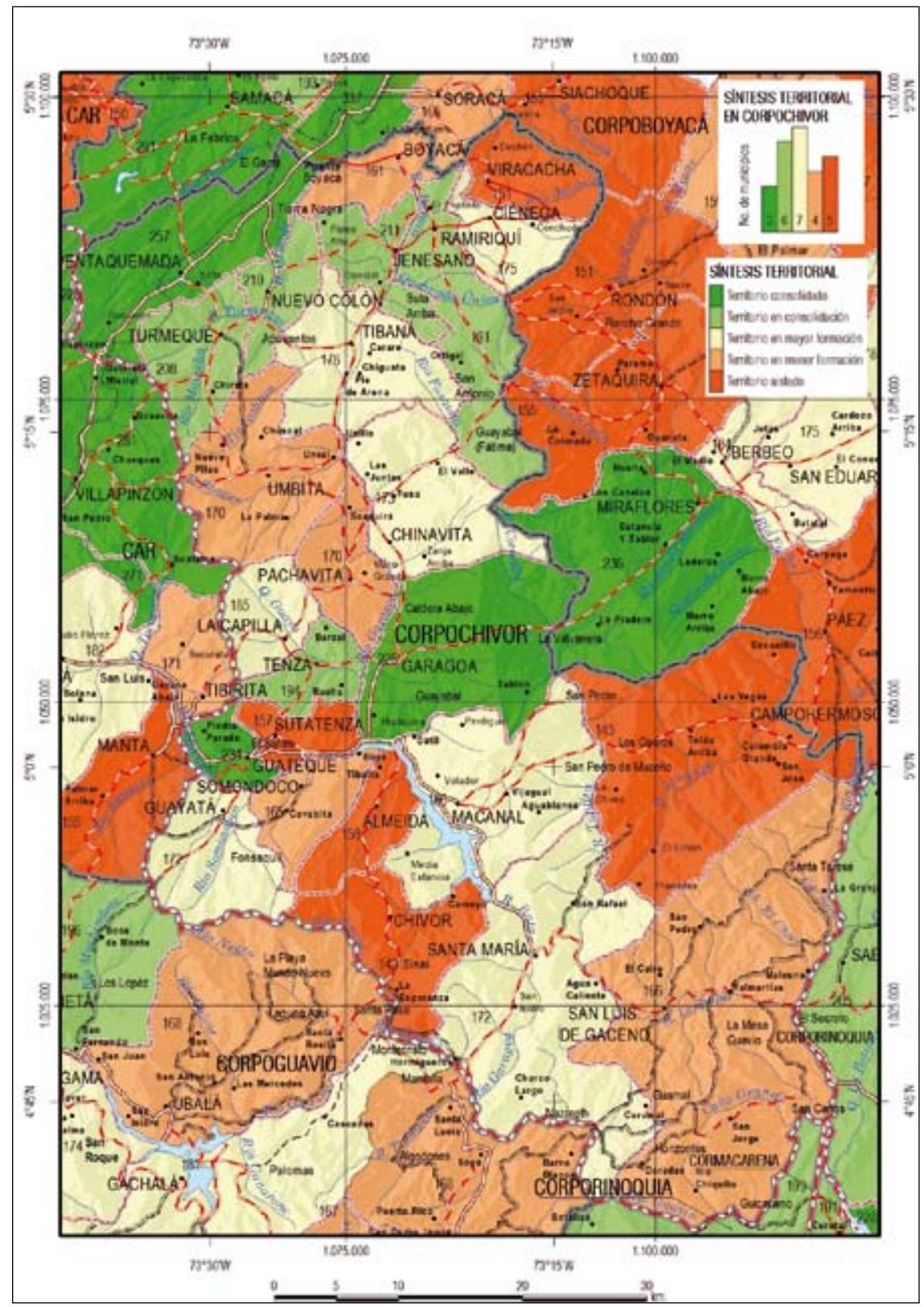

Fuente: elaboración propia. 
El viejo campesino que con orgullo lleva su ruana cardada y sombrero de ala corta, emprende su empinado camino, sendas heredadas de sus antepasados que recorren su historia. Otro, más joven, ya no va a caballo, se ve obligado a usar un casco y a quitarse la capa.

Figura 9. Lo que fue y lo que es la vereda de Tásvita.
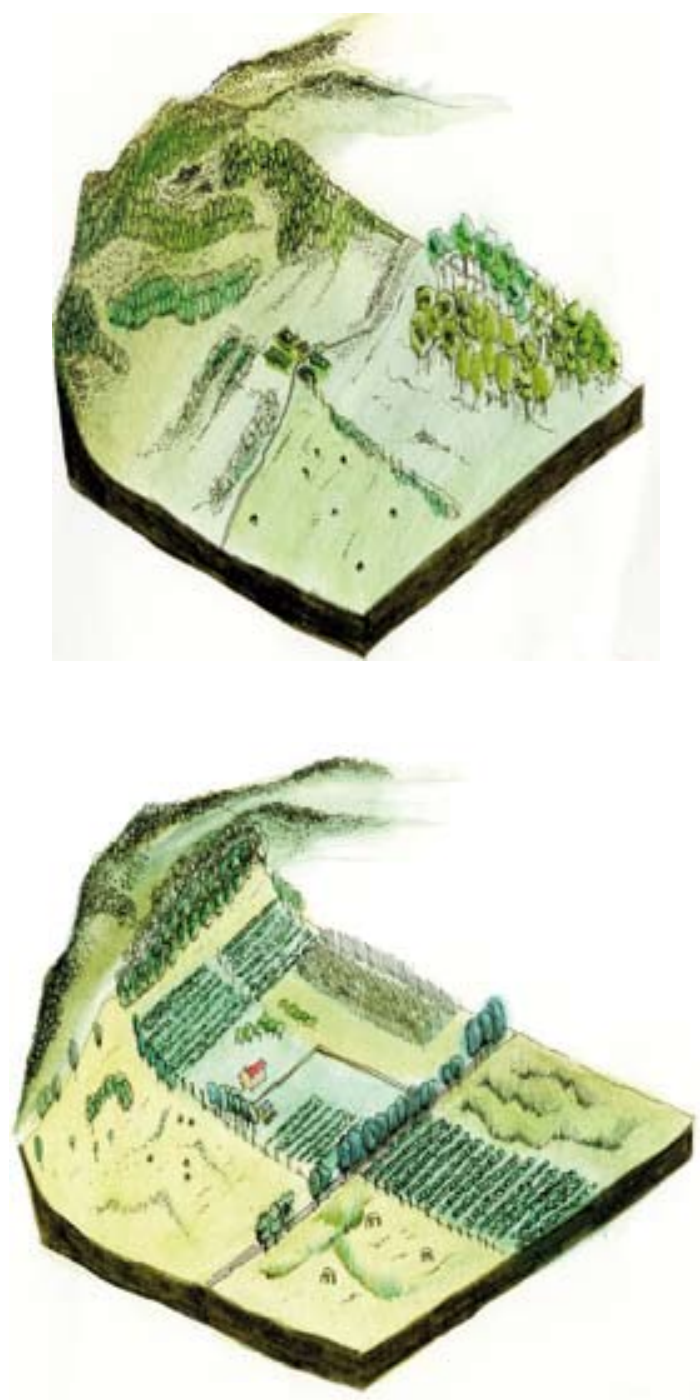

Fuente: elaboración propia. 
Los antiguos senderos de herradura, que el tiempo no borra, llevan el paso de lugareños y familias numerosas que recorren cada palmo de esta vereda. Aunque algunas tradiciones se conservan, ellos han ido cambiando el paisaje y el paisaje los ha ido cambiando a ellos. Este sitio no es el mismo. Ahora, otros son los árboles, los pájaros, la vestimenta, no se cultiva lo que se cultivaba antes (Figura 9). El paso de motos y camiones por la carretera es lo actual. Ya no va más el caballo al pueblo. Pero la memoria persiste, y su cultura rural, la de trabajar la tierra, del gran valor de la familia y del amor al campo, hacen parte de la colectividad de un pueblo que desde hace más de 230 años construye una tradición campesina que subsiste.

\section{Conclusiones}

La teoría del sistema GTP fue adaptada para la definición y construcción de las determinantes ambientales regionales en CORPOCHIVOR. Aportó elementos que orientan la planificación ambiental regional, en particular, la revisión, ajuste o modificación de los POT de la jurisdicción, con una visión regional, acorde al ámbito de gestión de la entidad.

Se identificaron elementos, componentes, relaciones, interacciones y funciones espacio-temporales del geosistema y territorio. En total, se integraron 17 conceptos al geosistema, en especial una propuesta de representación cartográfica de ecosistemas a escala general (1:100.000). También se identificaron 45 componentes del territorio agrupados en doce sub- síntesis y cuatro síntesis; de esta forma se ofrece a CORPOCHIVOR un importante acervo de conocimiento sistematizado y analizado para su jurisdicción.

Hay que reconocer que en el caso del paisaje socio-cultural no es posible abarcar una comprensión regional sin transitar desde lo local, lo cual supone un mayor alcance de lo propuesto por esta investigación. Se admite esta limitación en beneficio de la adaptación de la teoría GTP para la construcción de determinantes ambientales regionales. Además es necesario conformar grupos interdisciplinares e interprofesionales para abordar la comprensión local social, desde la antropología, la sociología, la sicología y otras disciplinas.

Se representaron cartográficamente las unidades de análisis espacial propuestas. En total se generaron 128 salidas cartográficas como un conjunto de herramientas que brindan la posibilidad de mejorar la comprensión geográfica y alimentan el conocimiento de la jurisdicción en CORPOCHIVOR.

A diferencia de las determinantes ambientales formuladas por CORPOCHIVOR, las determinantes ambientales regionales tienen en cuenta el ámbito de gestión de la entidad, parten de información pertinente con la escala de trabajo de la corporación, integran la visión territorial y ofrecen una posibilidad de vinculación con los aspectos socio-culturales.

Esta propuesta metodológica puede ser replicada en otras CAR porque los datos 
e información identificados en cada uno de los componentes tienen una cobertura nacional y son disponibles por entidades oficiales. Se destaca la aplicación del SIGOT como mecanismo de gestión de información para la planificación y el ordenamiento territorial.

Uno de los argumentos del planteamiento del problema de este trabajo es que existe una interpretación de lo "ambiental" como lo biofísico únicamente, reflejado en el énfasis biocentrista de la planificación ambiental regional. Una conclusión al respecto, y luego de formular la propuesta para unas determinantes "ambien- tales”, es que la gestión ambiental debe orientarse hacia los actores sociales, pues son quienes intervienen el territorio, y no hacia el énfasis tradicional de la gestión de los recursos naturales. La naturaleza tiene sus propias normas.

La formulación de determinantes ambientales, a partir de lo propuesto por el sistema GTP, es una oportunidad para integrar los aportes de diferentes ópticas sobre el mismo territorio. Los resultados de esta investigación constituyen una contribución a la comprensión sistémica e integral del territorio desde la geografía ambiental. 


\section{Literatura citada}

Bertrand, G. \& Bertrand, C. (2006). Geografía del medio ambiente. El sistema GTP: Geosistema, Territorio y Paisaje. Granada, España: Universidad de Granada.

Bertrand, G. \& Frolova, M. (2006). Geografía y paisaje. En D. Hiernaux-Nicolas (Ed.), Tratado de geografía humana (pp. 254-272). España: Anthropos.

Congreso de Colombia. (1997). Ley 388. Recuperado de http://www.secretariasenado.gov. co/senado/basedoc/ley/1997/ley_0388_1997.html

Corpochivor. (2007). Plan de gestión ambiental regional, 2007-2019. Garagoa, Boyacá. Recuperado de http://www.Corpochivor.gov.co/documentos/pdf/pgar2007_2019/ pgar2007_2019.pdf

Corpochivor. (2010). Atlas geográfico y ambiental de Corpochivor. Tunja, Boyacá: Salamandra Grupo Creativo S. A. S.

Corpochivor. (2011, marzo). Plan de acción para la atención de la emergencia y la mitigación de sus efectos, PAAEME, Recuperado de http://www.Corpochivor.gov.co/ documentos/pdf/paaeme/paaeme_2011.pdf

Instituto de Hidrología, Meteorología y Estudios Ambientales de Colombia IDEAM, Instituto Geográfico Agustín Codazzi IGAC, Instituto de Investigación de Recursos Biológicos Alexander Von Humboldt IAvH. et al. (2011). Mapa nacional de coberturas de la tierra, escala 1:100.000. Bogotá, Colombia.

Instituto Geográfico Agustín Codazzi IGAC (2010). Sistema de información geográfico para la planificación y el ordenamiento territorial, SIGOT. Instituto Geográfico Agustín Codazzi. Recuperado a partir de http://sigotn.igac.gov.co/sigotn/

Ministerio de Ambiente, Vivienda y Desarrollo Territorial. (2004). Decreto 1200. Recuperado de http://www.minambiente.gov.co//documentos/dec_1200_200404.pdf

Pissinati, M. C. \& Archela, R. S. (2009). Geossistema territorio e paisagem - método de estudo da paisagem rural sob a ótica bertrandiana. Geografia (Londrina), 18(1), 5-31.

Rodríguez, N., Armenteras, D., Morales, M., \& Romero, M. (2004). Ecosistemas de los Andes colombianos. Bogotá, Colombia.

Secretaría del Convenio sobre la Diversidad Biológica. (2004). Enfoque por ecosistemas. Recuperado de http://www.cbd.int/doc/publications/ea-text-es.pdf 
